\title{
REGULAR ARTICLE \\ INDUCED MUTAGENESIS IN CICER ARIETINUM BY THE APPLICATION OF EMS AND GAMMA RAYS WITH SPECIAL REFERENCE TO THE CYTOLOGICAL STUDIES
}

\author{
S. UMAVATHI ${ }^{1}$, I. ANITTHA ${ }^{2}$, L. MULLAINATHAN2 ${ }^{*}$ \\ ${ }^{1}$ Adhiyaman Arts and Science College for Women, Tamil Nadu, India
}

${ }^{2}$ Department of Botany, Annamalai University, Annamalai Nagar 608002, Tamil Nadu, India

\begin{abstract}
The present study was conducted to analyze the chemical and physical mutagenesis on Cicer arietinum with special reference to cytological studies. In this regard, $\mathrm{CO}-4$ variety of chick pea was subjected to different concentration of gamma rays (20, 30, $40,50$ and $60 \mathrm{kR})$ and $\mathrm{EMS}(10,20,30,40$ and $50 \mathrm{mmol})$ for inducing mutation. The $\mathrm{M}_{1}$ plants exposed to mutagen produces a clear cut difference from the untreated control. The root mitotic studies reveal a wide range of chromosomal aberrations such as stickiness, laggards, bridges and some other precocious movement. The percentage of abnormal cell increased with dosage in both mutagens; and 50 mmol EMS showed more chromosomal aberrations when compared to gamma rays.
\end{abstract}

Keywords: Chick pea, EMS, Gamma rays, Induced mutation, Chromosomal aberrations

\section{INTRODUCTION}

The breeding by means of mutation is the best way to enhance the qualities and yields in crop plants. In any case, a productive hereditary change of a cultivar relies upon the method of quality mutation and the interrelationship among plant characters [4]. Cicer arietinum L. is one among the highly cultivated crop plants in all parts of the word and is usually self-pollinated with diploid characteristics and $2 n=16$ chromosomes [1]. The extent of cytological changes in mitosis or meiosis is considered as a dependable feature for calculating the ability of mutagen [2].

The aims of this study were to analyze the cytological aberrations in chick pea due to the treatments with different mutagens.

\section{MATERIALS AND METHODS}

\section{Mutagenic treatment}

The seeds of chick pea variety $\mathrm{CO}-4$ obtained from Tamil Nadu, Agricultural University, Coimbatore, Tamil Nadu, India were used for the present study. The experimental material was divided in to three sets. The first sets of seeds were irradiated with different doses of $(20,30,40,50$ and 6okR) gamma rays from Indhira Gandhi Atomic Research Centre, Kalpakkam. For EMS treatment, the another set of seeds were presoaked in distilled water for $6 \mathrm{~h}$. The excess moisture in the seeds were removed and were treated with different concentration of (10, 20, 30, 40 and 50 mmol) freshly prepared aqueous solution of EMS in phosphate buffer ( $\mathrm{pH}$ 7.5) for 6 hours. The treated seeds were sown immediately after the treatment along with control seeds.

For the cytological studies, root tip squash studies were more adapted. One week after sowing, the fresh and young root tips were collected from 10-15 randomly selected $M_{1}$ seedlings from each concentration and fixed in 1:3 solution of acetic alcohol for $24 \mathrm{~h}$. The slides were prepared using the standard squash technique [3].

\section{Experimental results}

Chromosome and chromatid type aberrations can be detected microscopically in both metaphasic and anaphasic stages in the mitotic cell cycle. The mutagens which cause gene mutations also induce the chromosomal aberrations in plants. In chick pea, mitotic squash preparation becomes quite difficult due to the presence of globular structures. In the cytoplasm that hinder the staining, spreading and identification of chromosomes. The root mitotic studies revealed a wide range of chromosomal aberrations such as stickiness, metaphasic bridges, precocious movements, unequal separation, laggards, univalent and multivalent anaphasic bridges. Chick pea contains 8 bivalents $(2 n=16)$ which are small and recognizable at higher magnification $(10 X \times 100 X)$. The both mutagenic treatments displayed varying degrees of chromosomal aberrations. Lower dose/conc. of mutagens (20kR; $10 \mathrm{mmol} ; 20 \mathrm{mmol}$ ) revealed

Received o1 April 2018; Accepted 19 May 2018

${ }^{*}$ Corresponding Author

L. Mullainathan

Department of Botany, Annamalai University, Annamalai Nagar 608002, Tamil Nadu, India

Email: vishnumullai@gmail.com

(This article is open access and licensed under the terms of the Creative Commons Attribution License (http://creativecommons.org/licenses/by/4.o/) which permits unrestricted, use, distribution and reproduction in any medium, or format for any purpose, even commercially provided the work is properly cited. Attribution - You must give appropriate credit, provide a link to the license, and indicate if changes were made. 
more or less normal pairing with a low percentage of chromosomal anomalies compared to other concentrations. The spectrum and frequency of chromosomal aberrations and the total number of cells scored in both mutagenic treatments were represented in table 1 (Plate 1 and 2). A dose dependent increase in mitotic abnormalities was observed in both gamma rays and EMS. Chromosomal bridges, stickiness, precocious movements and unequal separations were observed at metaphasic stage. The stickiness and precocious movements were observed in almost all the dose/conc. and their frequency was very less compared to other chromosomal aberrations. The anaphasic stage was characterized by laggards, univalent and multivalent bridges. The total frequency of chromosomal aberrations was ranged from 3.44 to 8.54 per cent in gamma rays and 3.84 to 9.47 per cent in EMS. The most prominent chromosomal abnormalities induced by EMS were metaphasic univalent and multivalent bridges. While, that the gamma rays were most prominent in inducing higher frequencies of laggard and anaphasic multivalent bridges. The higher dose/conc. of gamma rays and EMS induces highest per cent of stickiness and unequal separations. The precocious movements were observed at moderate doses in EMS and higher doses in gamma rays. Among the different dose/conc. of treatments studied, 50 mmol of EMS and $60 \mathrm{kR}$ of gamma rays was reported the highest percentage of chromosomal aberrations, and EMS is found to be more effective when compared to gamma rays.

\section{Plate 1: Mitotic abnormalities}

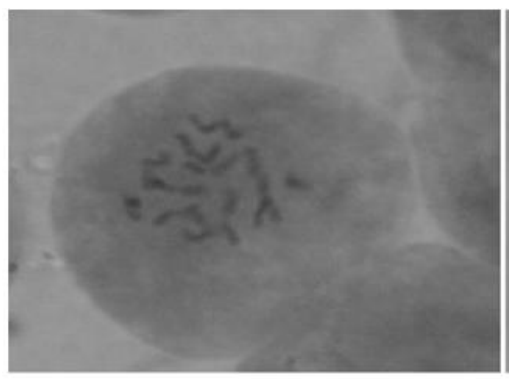

Metaphase $(2 n=16)$ Control

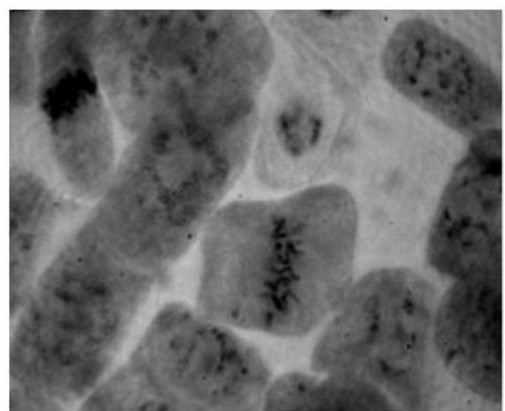

Precocious movement $(10 \mathrm{mM})$

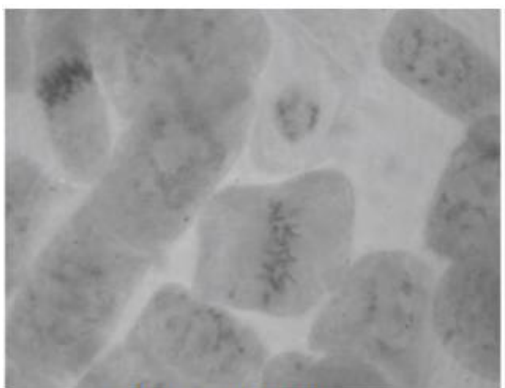

Stickiness (40mM)

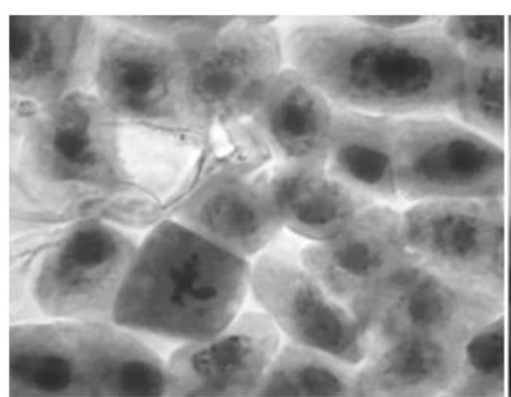

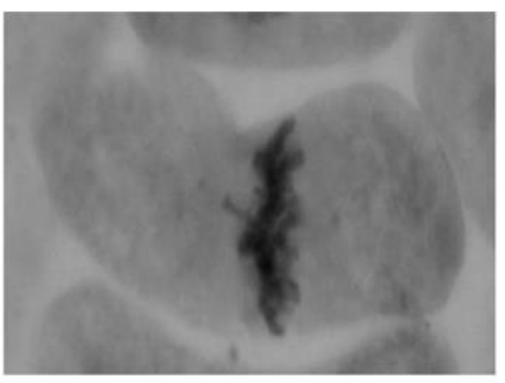

Laggard (40kR)

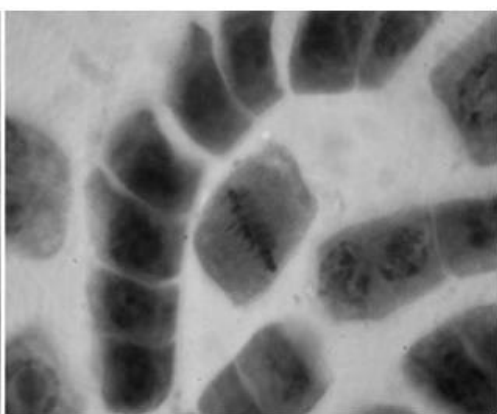

Precocious movement (20kR)

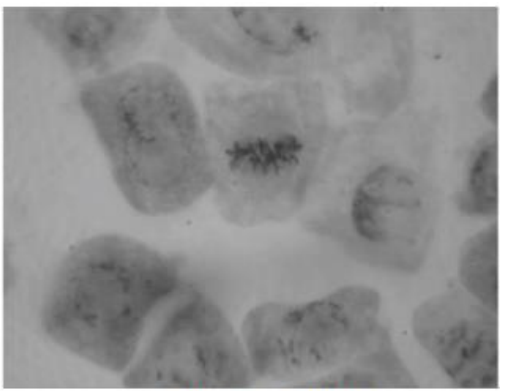

Stickiness (40kR)

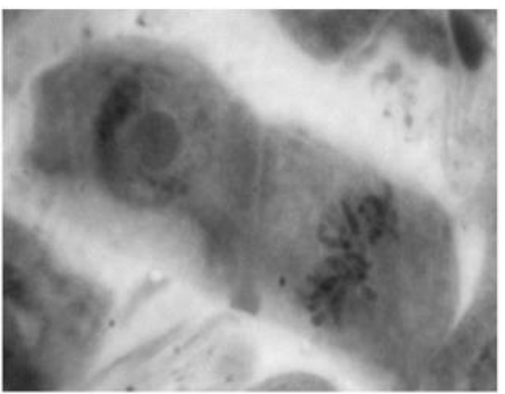


Plate 2: Mitotic abnormalities

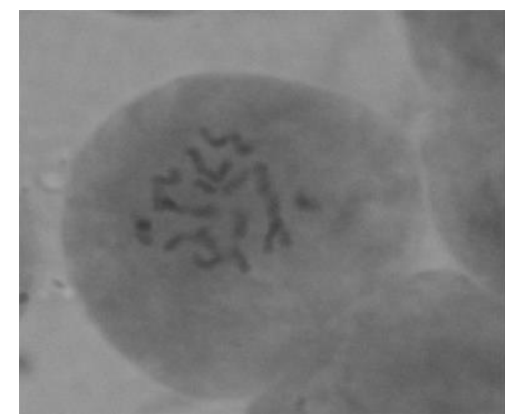

Control (2n=16)

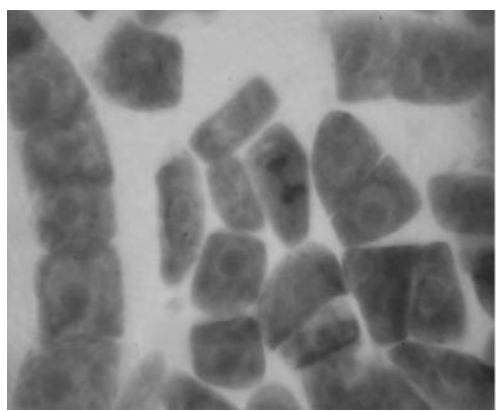

Univalent bridge (30 mmol)

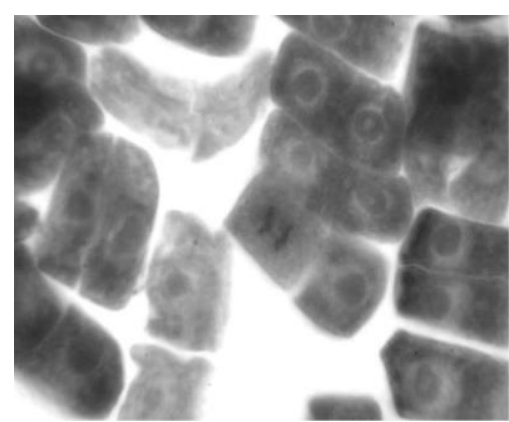

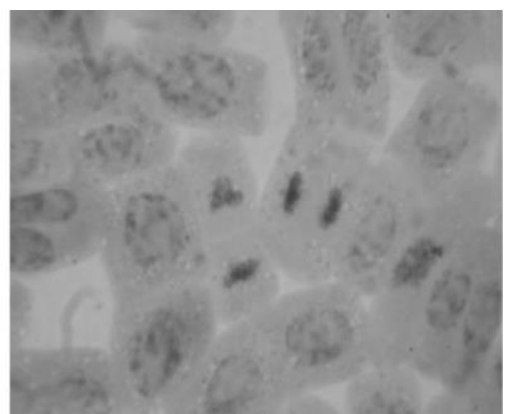

Anaphase (Control)

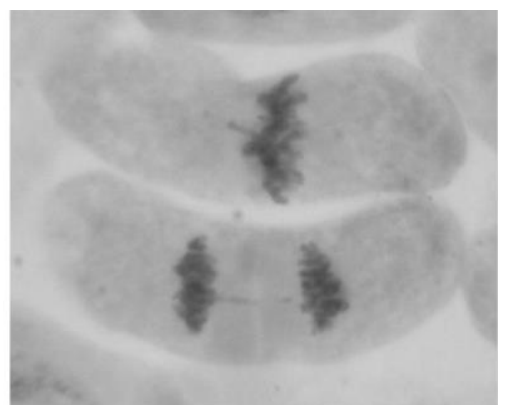

Univalent bridge (3okR)

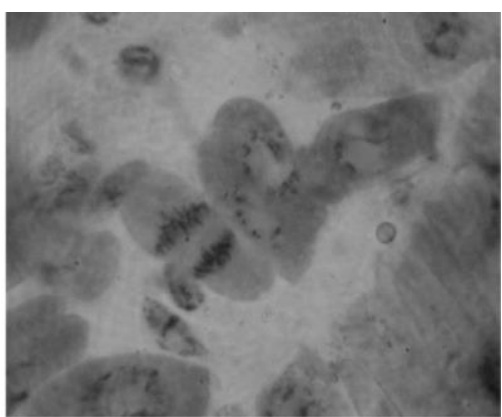

Table 1: Frequency of mitotic abnormalities in various mutagenic treatments in $M_{1}$ generation of chick pea

\begin{tabular}{|c|c|c|c|c|c|c|c|c|c|c|c|}
\hline \multirow[t]{2}{*}{ Mutagens } & \multirow[t]{2}{*}{ Treatments } & \multirow{2}{*}{$\begin{array}{l}\text { Total } \\
\text { number of } \\
\text { root tip cells }\end{array}$} & \multicolumn{4}{|c|}{ Metaphase } & \multicolumn{3}{|c|}{ Anaphase } & \multirow{2}{*}{$\begin{array}{l}\text { Total number } \\
\text { of abnormal } \\
\text { cells }\end{array}$} & \multirow{2}{*}{$\begin{array}{l}\text { Total } \\
\text { frequency } \\
(\%)\end{array}$} \\
\hline & & & $\mathbf{B}$ & $\mathbf{S}$ & PM & US & $\mathbf{U}$ & $\mathbf{M}$ & $\mathbf{L}$ & & \\
\hline \multirow{7}{*}{$\begin{array}{l}\text { Control } \\
\text { Gamma } \\
\text { rays }\end{array}$} & - & 199 & - & - & - & - & - & - & - & - & - \\
\hline & $20 \mathrm{kR}$ & 204 & 0.49 & - & - & - & 0.49 & - & - & 2 & 0.98 \\
\hline & $30 \mathrm{kR}$ & 198 & 1.01 & 0.50 & 0.50 & - & 0.50 & 1.01 & 1.01 & 9 & 4.54 \\
\hline & $40 \mathrm{kR}$ & 227 & 0.88 & 0.44 & 0.88 & 0.44 & 0.88 & 1.32 & 1.32 & 14 & 6.16 \\
\hline & $50 \mathrm{kR}$ & 212 & 0.47 & 1.41 & 0.94 & 0.94 & 0.47 & 1.88 & 1.41 & 16 & 7.54 \\
\hline & $60 \mathrm{kR}$ & 199 & 1.50 & 1.50 & 1.50 & 1.00 & 0.50 & 1.00 & 2.51 & 17 & 8.54 \\
\hline & Total & 1040 & 0.86 & 0.57 & 0.76 & 0.48 & 0.57 & 1.05 & 1.25 & 58 & $\mathbf{5 . 5 7}$ \\
\hline \multirow[t]{7}{*}{ EMS } & $10 \mathrm{mmol}$ & 208 & 0.92 & 0.48 & 0.48 & - & 0.48 & 0.92 & 0.48 & 8 & 3.84 \\
\hline & $20 \mathrm{mmol}$ & 196 & 1.02 & 0.51 & 0.51 & 1.02 & 1.02 & 0.51 & 1.02 & 11 & 5.61 \\
\hline & $30 \mathrm{mmol}$ & 200 & 1.50 & 0.50 & 1.00 & 0.50 & 1.50 & 1.50 & 1.00 & 15 & $7 \cdot 50$ \\
\hline & $40 \mathrm{mmol}$ & 195 & 2.56 & - & 0.51 & 1.02 & 1.15 & 1.02 & 1.02 & 16 & 8.00 \\
\hline & $50 \mathrm{mmol}$ & 190 & 1.05 & 1.05 & - & 1.57 & 2.63 & 2.10 & 1.05 & 18 & 9.47 \\
\hline & Total & 989 & 1.41 & 0.50 & 0.50 & 0.80 & 1.41 & 1.21 & 0.91 & 68 & 6.87 \\
\hline & Overall & 2024 & 1.13 & 0.54 & 0.64 & 0.64 & 0.98 & 1.13 & 1.03 & 126 & 6.22 \\
\hline
\end{tabular}

B-Bridge, S-Stickiness, PM-Precocious movement, US-Unequal separation, U-Univalent, M-Multivalent, L-Laggard

\section{DISCUSSION}

The mitotic behavior is a reliable index to measure the effectiveness of any mutagen. It gives the response of various genotypes to particular mutagens and provides grate chances for the selection of desired characters.
Cytological aberrations in plants serve as an excellent monitoring system for the detection of chemicals that may cause genetic hazards. In this study, a wide range of chromosomal aberrations includes stickiness, metaphasic bridges, precocious movements, unequal separation, laggards, univalent and multivalent anaphasic bridges 
were observed. Tamas Elena [4] reported various types of mitotic aberrations such as dominant fragments, stickiness, precocious separations, C-metaphase, ring chromosome, unequal separation, laggards, bridges and micronuclei in Faba bean. The frequency of chromosomal aberrations was increased with increasing dose/conc. in both gamma rays and EMS. These results were supported by earlier work done by $[5,6]$. The frequency of anaphasic and metaphasic bridges was higher in both mutagenic treatments. They were pronounced due to the subchromatid exchanges, unequal exchanges or by the formation of dicentric chromosomes [7]. The disturbed homology of chromosome pairing or disturbed spindle mechanism results in the precocious separations of chromosome. And also the abnormal spindle formation produces laggards and stickiness at higher dose/conc. of mutagenic treatments [8and9]. Among the physical and chemical mutagens, the maximum abnormalities both structured and behavioral were induced by EMS than gamma rays. EMS induced more chromosomal variations and biological alterations in Maize [8] and in Chilli [10]. Chemical mutagenesis in Dianthus was reported earlier [11], and these type of induced mutations are highly useful in mutation breeding strategies.

\section{CONCLUSION}

Cytological analysis for the mitotic studies in M1 generation revealed wide range of chromosomal aberrations such as stickiness, bridges, precocious movements, unequal separations, laggards and univalent and multivalent anaphasic bridges. The highest frequency of chromosomal aberrations was observed at $50 \mathrm{mmol}$ in EMS followed by 6okR in gamma rays.

\section{REFERENCES}

1. Van der Maesen, L. J. G., 1987. Cicer L. Origin, history and taxonomy of chickpea. In: M. C. Saxena and K. B.
Singh (eds.), The Chickpea, 11-34. CAB International, U. K.

2. Siddiqui, S., M. K. Meghvansi and Z. Hasan, 2007. Cytogenetic changes induced by sodium azide ( $\left.\mathrm{NaN}_{3}\right)$ on Trigonella foenum graecum L. seeds. South African Journal of Botany, 73:632-635.

3. Marimuthu, K. M. and M. K. Subramaniam, 1960. Haematoxylin squash method for the root tip of Dolichos lab lab L. Curr. Sci., 29:482-493.

4. Tamas Elena, 2010. Comparative analysis of mitotic and meotic aberrations induced by Diethyl sulphate and Dimethyl sulphate in Faba bean (Vicia faba L.). Agricultura-Stiinta Si Practica, 3: 75-76.

5. Sharma, V., and G. Kumar, 2004. Meiotic Studies in Two Cultivars of Cicer arietinum L. after EMS treatment. Cytologia, 69: 243-248.

6. Datta, S., H. Niwa and K. Itoh, 2003. Prevalence of 11 pathogenic genes of Campylobacter jejuni by PCR in strains isolated from humans, poultry meat and broiler and bovine faeces. J. Med. Microbiol. 52:345348 .

7. Suganthi, C. P., and V. R. K. Reddy, 1992. Effects of gamma rays and EMS on meiosis in some cereals. J. Cytol. Genet. 27, 103114.

8. Tarar, J. L., and V. R. Dnyansagar, 1980. Comparison of ethyl methane sulphonate and radiation induced meiotic abnormalities in Turnera ulmifolia Linn. var. angustifolia Wild. Cytologia 45, 221-231.

9. Kumar, G. and A. Tripathi, 2004. Mutagenic response of caffeine in Capsicum annuum L. Journal of Indian Botanical Society, 83:136-140.

10. Kumar, G., and P. K. Rai, 2007. EMS Induced Karyomorphological Variations in Maize (Zea mays L.) Inbreds. Turk. J. Biol., 31:187-195.

11. Roychowdhury R, Tah J. Chemical mutagenic action on seed germination and related agro-metrical traits in M1 Dianthus generation. Current Botany. 2011;2(8):19-23. 